\title{
Availability, Management and Use of Priority Life-Saving Medicines for Under-Five Children in Two Health Districts in Senegal: A Cross-Sectional Study
}

\author{
Oumar Bassoum1,2*, Abou Ba ${ }^{3,4}$, Alioune Badara Tall5, Oumou Khaïry Kane6, Adama Faye1,2, \\ Ibrahima Seck ${ }^{1,2}$, Anta Tal-Dia1,2 \\ ${ }^{1}$ Department of Preventive Medicine and Public Health, Faculty of Medicine, Pharmacy and Odontology, Cheikh Anta Diop \\ University, Dakar, Senegal \\ ${ }^{2}$ Institute of Health and Development, Cheikh Anta Diop University, Dakar, Senegal \\ ${ }^{3}$ University Service of Pediatrics, Faculty of Medicine, Pharmacy and Odontology, Cheikh Anta Diop University, Dakar, Senegal \\ ${ }^{4}$ National Hospital Center Dalal Jam, Dakar, Senegal \\ ${ }^{5}$ Department of Community Health, Alioune Diop University, Bambey, Senegal \\ ${ }^{6}$ Faculty of Medicine, Pharmacy and Odontology, Cheikh Anta Diop University, Dakar, Senegal \\ Email: ^bassoum.oumar@gmail.com, oumar.bassoum@ucad.edu.sn
}

How to cite this paper: Bassoum, O., Ba, A., Tall, A.B.., Kane, O.K., Faye, A., Seck, I. and Tal-Dia, A. (2020) Availability, Management and Use of Priority Life-Saving Medicines for Under-Five Children in Two Health Districts in Senegal: A Cross-Sectional Study. Health, 12, 204-218.

https://doi.org/10.4236/health.2020.122017

Received: October 19, 2019

Accepted: February 17, 2020

Published: February 20, 2020

Copyright $\odot 2020$ by author(s) and Scientific Research Publishing Inc. This work is licensed under the Creative Commons Attribution International License (CC BY 4.0).

http://creativecommons.org/licenses/by/4.0/

\section{(c) (i) Open Access}

\begin{abstract}
Under-five mortality remains a major concern in the world and in Senegal. It is mainly due to preventable and treatable diseases with priority life-saving medicines for under-five children. This study evaluated the availability, management and use of these drugs in two health districts in Senegal. A descriptive cross-sectional study was conducted in the health districts of Guediawaye and Pete from 01 November 2018 to 31 January 2019. The health district of Guediawaye is in the region hosting the Senegalese capital while that of Pete is located in the region of Saint Louis, northern Senegal. Nine drugs that can prevent and treat malaria, diarrhea, pneumonia and malnutrition were selected. An inventory form and a self-administered questionnaire were used to collect data that was analyzed with SPSS and expressed as a percentage and average. Drug availability was $50.4 \%$ and $54.3 \%$ in Guediawaye and in Pete, respectively. Average stock-out duration in the past three months was estimated at 22.6 and 26 days, respectively. The drug management was marked, on the one hand, by a good availability of stock cards in the two districts with proportions equal to $100 \%$ and $94.1 \%$, respectively, and on the other hand, by the presence of expired stocks in Pete (12.2\%). About $79 \%$ and $88 \%$ of prescribers reported prescribing the basket drug, respectively. These results show that access to priority life-saving medicines for children remains a challenge.
\end{abstract}


Measures to be taken should include improving the distribution channels and training of health professionals. Further studies should be conducted in other health districts to better understand the barriers to access to child health services.

\section{Keywords}

Priority Life-Saving Medicines, Access, Under-Five Children, Senegal

\section{Introduction}

In 2017, according to the World Health Organization (WHO), 5.4 million under-five children died, equal to under-five mortality rate (U5MR) of 39 deaths per 1000 live births. This rate is higher in sub-Saharan Africa (SSA) with 76 deaths per 1000 live births [1]. In Senegal, this indicator is 56 deaths per 1000 live births [2]. If current trends continue, the perspectives up until 2030 will be alarming. Indeed, between 2016 and 2030, 69 million deaths of under-five children would be recorded, including 3.6 million in the year 2030 alone. The SSA would still pay the highest price since it would concentrate more on half of the deaths [3]. More than one out of every two deaths is due to diseases that can be treated with high-quality and low-cost drugs [4]. The main causes are preventable communicable diseases [5]. Nearly 52\% of these children died of pneumonia, diarrhea and malaria [6]. U5MR is directly or indirectly related to malnutrition in $45 \%$ of cases [6].

Improving child health has long been a global priority [7]. Thus, several initiatives were taken. In 2000, the United Nations defined the Millennium Development Goals (MDGs) [3]. Objective 4 aimed at reducing by two-thirds U5MR during the period 1990-2015. This mortality increased from 90 to 43 deaths per 1000 live births during this period [3]. The goal has not been achieved. This has led to the development of the Sustainable Development Goals (SDGs), of which one of the major targets is the reduction of U5MR to 25 deaths per 1000 live births at most [3]. In order to achieve this goal, progress will have to continue at a faster pace than that achieved under the MDGs [3]. In 2007, WHO developed the first list of essential medicines for children [8] to help countries achieve MDG 4 [9]. In 2011, WHO published a list of priority medicines for mothers and children [10]. The publication of this list coincided with the meeting of the eighteenth Expert Committee on the Selection and Use of Essential Drugs. In 2012, the United Nations Commission on Life-Saving Commodities for Women and Children identified thirteen underutilized, low-cost and high-impact commodities [11]. The recommendations formulated at these meetings resulted in the updating of the list, which has become the list of priority life-saving medicines for women and children [7]. These drugs can prevent and treat most of the diseases that cause U5MR [11] [12]. 
Senegal has developed a National Drug Policy (NDP), with the aim of ensuring the availability, accessibility and rational use of essential medicines [13]. The Ministry of Health and Social Action (MHSA) has integrated most of the drugs for children into the national list of essential medicines [14]. A plan to secure vital products is developed and implemented as part of a tripartite partnership that includes the National Pharmacy Supply, the Directorate of Pharmacy and Drug (DPG) and the National Laboratory for Medicine Quality Control. This plan aims to improve the accessibility of these products [15]. However, this accessibility is influenced by several factors including the selection, availability and use of essential drugs [8]. Monitoring these factors helps to determine the performance and adequacy of health systems in accessing essential medicines [16].

The availability of medicines for children is low in developing countries [8] [9] [17] [18]. This situation is also reported in Senegal with fewer than seven out of ten health facilities (HFs) that had at least one priority drug [19]. However, the availability of all priority life-saving medicines for under-five children has not been evaluated, as well as their use and availability of management tools. It was found necessary to carry out this study with a view to contributing to the production of new data to inform and reinforce policies aimed at improving child health.

The objective of this study was to assess the availability, management and use of priority life-saving medicines for under-five children.

\section{Method}

\subsection{Study Settings}

The study was conducted in the health districts (HDs) of Guediawaye and Pete. The HD of Guediawaye is located in the department of the same name which is a suburb of the Senegalese capital, Dakar. In 2018, the number of inhabitants was estimated at 381,476 of which 62,829 under-five children. The HD housed thirteen and seven public and private HFs respectively. The public sector consisted of one health center (HC) and twelve health posts (HPs) versus two clinics and five HPs for the private sector [20]. The HD of Pete is located in the department of Podor and in the region of Saint Louis, in northern Senegal [21]. In 2018, its population was estimated at 187,342 inhabitants, including 30,855 under-five children [21]. This HD is rural and included 28 public HFs including two HCs and 26 HPs [21].

\subsection{Type and Period of Study}

The study was cross-sectional and descriptive and took place between November 01, 2018 and January 31, 2019.

\subsection{Study Population}

The study population consisted of HFs, prescribers and pharmaceutical depot managers. 


\subsection{Sampling}

\subsubsection{Selection of HFs and Health Professionals}

All HFs that have been in existence at least six months before the study were targeted. In each HF, health professionals who were present on the day of the survey, who were involved in the management of childhood diseases and who agreed to participate in the study were recruited.

\subsubsection{Selection of Medicines and Products from the Basket}

Nine medicines and health products were selected. These included amoxicillin $250 \mathrm{mg}$ dispersible tablet (DT), vitamin A 100,000 IU capsules, vitamin A 200,000 IU capsules, zinc $20 \mathrm{mg}$ DT, oral rehydration salt (ORS), artesunate 50 mg suppository, artesunate $200 \mathrm{mg}$ suppository, artemether/lumefantrine combination DT (ACT) and ready-to-use therapeutic foods (RUTFs). The choice of these commodities was mainly explained for three reasons. First, apart from RUTFs, they all appear on the WHO list of Priority Life-Saving Medicines for Children [7]. Second, they are included in Senegal's national list of essential medicines [14]. Third, these commodities, with the exception of ACT, are part of the list of the seventeen vitally important products established by the MHSA and are subject to a security plan for their permanent availability at the HFs [15].

\subsection{Collection of Data}

\subsubsection{Data Collection Tools}

Two data collection tools were used and organized into four themes that are related to priority life-saving medicines for children: 1) availability, 2) management, 3) utilization and 4) training and supervision of health professionals. The first collection instrument was an inventory form that included all the names of the drugs. It was used to assess the availability and management of drugs. The second instrument was a questionnaire. It was used to collect information on the use of medicines as well as the training and supervision of health professionals in the management and use of priority life-saving medicines for children in the last 12 months preceding the survey. These collection tools were developed on the basis of a literature review [22] [23] and the experience of the research project members in conducting public health surveys and their strong knowledge about the organization of the health system and the provision of care. A pre-test of these tools was done in a HD located in the department of Dakar. The co-authors reviewed and commented on the collection tools before and after the pre-test.

\subsubsection{Collection Method}

Data was collected by two interviewers previously trained on survey objectives and modes of questionnaire administration. The data collectors conducted inventory controls to check the availability of valid drugs, expired drugs and stock cards. Drug use, availability of pharmacovigilance form, training and supervision were verified using self-administered questionnaire. 


\subsubsection{Operational Definition of Variables}

Each medicine of the basket was considered available when it was in stock on the day of the survey and had an expiry date not exceeded.

Stock-out was evaluated for any medicine of the basket that had already been in stock.

The availability of the stock cards was evaluated for both available drugs and those that were out of stock on the day of the survey.

\subsection{Data Entry and Analysis}

Data was entered on an Excel file and imported to SPSS for descriptive statistical analysis. The following indicators were calculated according to the methods identified through the literature [16] [24] [25] [26].

\subsubsection{Availability}

Proportion of HFs in which the drugs/products of the basket were available on the day of the survey.

Proportion of HFs where any drug/product of the basket has never been in stock.

Average stock-out duration in the three months preceding the survey.

\subsubsection{Management}

Proportion of HFs in which a stock card was established for each drug of the basket.

Proportion of HFs in which expired samples of drugs of the basket were seen.

Proportion of interviewed prescribers having the pharmacovigilance form.

\subsubsection{Use}

Proportion of prescribers using ACT DT for the management of uncomplicated malaria.

Proportion of prescribers using artesunate suppository for the management of severe malaria.

Proportion of prescribers using ORS/Zinc for the management of diarrhea.

Proportion of prescribers using amoxicillin $250 \mathrm{mg}$ DT for the management of pneumonia.

\subsubsection{Training/Supervision of Health Professionals}

Proportion of trained/supervised pharmaceutical depot managers in the management of priority life-saving medicines for under-five children in the last twelve months.

Proportion of prescribers trained/supervised in the use of priority life-saving medicines for under-five children in the last twelve months.

\subsection{Ethical Considerations}

The study obtained the ethical approval of the Research Ethics Committee of the Cheikh Anta Diop University. An authorization was sought from District Medi- 
cal Officers (DMOs). To facilitate participation and ensure the transparency of the study, two notes were addressed to health professionals. One was written by the DMO inviting health professionals to participate in the survey. The other was written by the survey supervisor and outlined goals and expected outcomes. All respondents signed free and informed consent after reading both notes. No explanation was asked to those who refused to participate in the survey. Data was collected at down times. Anonymity and confidentiality were respected.

\section{Results}

\subsection{Response Rate}

The study took place in all twenty HFs of the Guediawaye HD. In Pete, among the twenty-eight targeted HFs, two were not included because of a refusal for one and the absence of the head nurse for the other. The pharmaceutical depot managers were thirteen and twenty-six, respectively. The number of prescribers who participated in the survey was twelve and twenty-eight, respectively.

\subsection{Availability}

\subsubsection{Availability on the Day of the Survey}

Priority-life saving medicines for children under-five children were not in stock in the private HFs of the Guediawaye HD. In the public sector, drugs were available in 50.4\% of HFs. Amoxicillin $250 \mathrm{mg}$ DT, vitamin A 100,000 IU capsules, artesunate $50 \mathrm{mg}$ suppository and artesunate $200 \mathrm{mg}$ suppository were not available in any HF. In contrast, Zinc $20 \mathrm{mg}$ DT, ORS, vitamin A 200,000 IU capsules, ACT tablets and RUTFs were more available with proportions ranging from $84.6 \%$ to $92.3 \%$ (Table 1 ).

In the Pete $\mathrm{HD}$, the average availability was $54.3 \%$ and varied from one drug to another. Zinc $20 \mathrm{mg}$ DT, ORS, vitamin A 200,000 IU capsules, as well as

Table 1. Basket drug availability on the day of the survey.

\begin{tabular}{ccccccc}
\hline & \multicolumn{3}{c}{ Guediawaye $(\mathrm{N}=20)$} & \multicolumn{2}{c}{ Pete $(\mathrm{N}=26)$} \\
\cline { 2 - 5 } Drug names & Public $(\mathrm{N}=13)$ & Private $(\mathrm{N}=7)$ & & \\
\cline { 2 - 5 } & $\mathrm{n}$ & $\%$ & $\mathrm{n}$ & $\%$ & $\mathrm{n}$ & $\%$ \\
\hline Amoxicillin 250 mg DT & 0 & 0.0 & 0 & 0.0 & 7 & 26.9 \\
ORS sachet & 12 & 92.3 & 0 & 0.0 & 21 & 80.8 \\
Zinc 20 mg DT & 11 & 84.6 & 0 & 0.0 & 22 & 84.6 \\
Vitamin A 100,000 UI capsules & 0 & 0.0 & 0 & 0.0 & 0 & 0.0 \\
Vitamin A 200, 000 UI capsules & 12 & 92.3 & 0 & 0.0 & 21 & 80.8 \\
ACT DT & 12 & 92.3 & 0 & 0.0 & 6 & 23.1 \\
Artesunate 50 mg suppository & 0 & 0.0 & 0 & 0.0 & 12 & 46.2 \\
Artesunate 200 mg suppository & 0 & 0.0 & 0 & 0.0 & 12 & 46.2 \\
RUTFs & 12 & 92.3 & 0 & 0.0 & 26 & 100.0 \\
Total & 59 & 50.4 & 0 & 0.0 & 127 & 54.3 \\
\hline
\end{tabular}


RUTFs were the most available products with proportions that ranged from $80.6 \%$ to $100 \%$. Vitamin A 100,000 IU capsules were not present in any HF. Amoxicillin $250 \mathrm{mg}$ DT and ACT DT were available in $26.9 \%$ and $23.1 \%$ of HFs (Table 1).

\subsubsection{Drugs of the Basket That Have Never Been in Stock}

In Guediawaye, the proportion of public HFs in which any drug of the basket was never in stock was $26.5 \%$. This situation involved amoxicillin $250 \mathrm{mg}$ DT (23.1\%), artesunate $50 \mathrm{mg}$ suppository (100\%), artesunate $200 \mathrm{mg}$ suppository (100\%), ACT DT (7.7\%) and RUTFs (7.7\%). Not all drugs in the basket have ever been stored in the private sector (Table 2).

As for the Pete's DS, this indicator was $12.4 \%$ and varied from one drug to another. Artesunate $50 \mathrm{mg}$ suppository and artesunate $200 \mathrm{mg}$ suppository have never been in stock in 50\% HFs versus $11.5 \%$ for amoxicillin $250 \mathrm{mg}$ DT (Table 2).

\subsubsection{Average Stock-Out Duration for the Drug Basket}

The average stock-out duration during the three months preceding the survey was 22.6 and 26 days in Guediawaye and Pete, respectively. However, this indicator varied from one drug to another. In Guediawaye, amoxicillin $250 \mathrm{mg}$ DT was broken for 87.3 days. It is the same for vitamin A 100,000 capsules (86.5 days) in Pete (Table 3).

\subsection{Stock, Quality and Safety Management}

\subsubsection{Availability of the Stock Card}

A stock card was established for each drug in all public HFs of Guediawaye (100\%). This indicator was $94.1 \%$ in Pete (Table 4 ).

\subsubsection{Stockpiling of Outdated Drugs and Health Products}

In the $\mathrm{HD}$ of Guediawaye, no medicine of the basket was out of date. However,

Table 2. Drugs of the basket that have never been in stock.

\begin{tabular}{ccccccc}
\hline & \multicolumn{3}{c}{ Guediawaye $(\mathrm{N}=20)$} & \multirow{2}{*}{ Pete $(\mathrm{N}=26)$} \\
\cline { 2 - 5 } Drug names & Public $(\mathrm{N}=13)$ & Private $(\mathrm{N}=7)$ & & \\
\cline { 2 - 5 } & $\mathrm{n}$ & $\%$ & $\mathrm{n}$ & $\%$ & $\mathrm{n}$ & $\%$ \\
\hline Amoxicillin 250 mg DT & 3 & 23.1 & 7 & 100 & 3 & 11.5 \\
ORS sachet & 0 & 0 & 7 & 100 & 0 & 0 \\
Zinc 20 mg DT & 0 & 0 & 7 & 100 & 0 & 0 \\
Vitamin A 100,000 UI capsules & 0 & 0 & 7 & 100 & 0 & 0 \\
Vitamin A 200,000 UI capsules & 0 & 0 & 7 & 100 & 0 & 0 \\
ACT DT & 1 & 7.7 & 7 & 100 & 0 & 0 \\
Artesunate 50 mg suppository & 13 & 100 & 7 & 100 & 13 & 50 \\
Artesunate 200 mg suppository & 13 & 100 & 7 & 100 & 13 & 50 \\
RUTFs & 1 & 7.7 & 7 & 100 & 0 & 0.0 \\
Total & 31 & 26.5 & 63 & 100 & 29 & 12.4 \\
\hline
\end{tabular}


Table 3. Average stock-out duration (days).

\begin{tabular}{ccc}
\hline Drug names & Guediawaye & Pete \\
\hline Amoxicillin 250 mg DT & 87.3 & 62.6 \\
ORS sachet & 0.5 & 10 \\
Zinc 20 mg DT & 7.7 & 7.8 \\
Vitamin A 100,000 UI capsules & 71.5 & 86.5 \\
Vitamin A 200,000 UI capsules & 2.8 & 13.3 \\
ACT DT & 0.0 & 25.4 \\
Artesunate 50 mg suppository & NA & 6.9 \\
Artesunate 200 mg suppository & NA & 6.9 \\
RUTFs & 00 & 0.0 \\
Total & 22.6 & 26 \\
\hline
\end{tabular}

NA $=$ Not Applicable

Table 4. Availability of the stock card and expired stock.

\begin{tabular}{ccccc}
\hline & \multicolumn{2}{c}{ Guediawaye } & \multicolumn{2}{c}{ Pete } \\
\cline { 2 - 5 } Drug names & $\begin{array}{c}\text { Stock card } \\
(\%)\end{array}$ & $\begin{array}{c}\text { Expired } \\
\text { stock }(\%)\end{array}$ & $\begin{array}{c}\text { Stock card } \\
(\%)\end{array}$ & $\begin{array}{c}\text { Expired } \\
\text { stock (\%) }\end{array}$ \\
\hline Amoxicillin 250 mg DT & 100 & 0 & 91.3 & 0.0 \\
ORS sachet & 100 & 0 & 100.0 & 3.8 \\
Zinc 20 mg DT & 100 & 0 & 100.0 & 3.8 \\
Vitamin A 100,000 UI & 100 & 0 & 92.3 & 23.1 \\
Vitamin A 200,000 UI & 100 & 0 & 92.3 & 3.8 \\
ACT DT & 100 & 0 & 100.0 & 61.5 \\
Artesunate 50 mg suppository & NA & NA & 76.9 & 0.0 \\
Artesunate 200 mg suppository & NA & NA & 76.9 & 0.0 \\
RUTFs & 100 & 0 & 100.0 & 0.0 \\
Total & 100 & 0 & 94.1 & 12.2 \\
\hline
\end{tabular}

NA = Not Applicable

expired samples were found in $12.2 \%$ of HFs of Pete and the most relevant products were vitamin A 100,000 IU capsules (23.1\%) and ACT DT (61.5\%) (Table 4).

\subsubsection{Availability of the Pharmacovigilance Form}

In Guediawaye, $75 \%$ (9/12) of the prescribers surveyed reported holding the pharmacovigilance form against 39\% (11/28) in Pete.

\subsection{Use of the Drug Basket}

In Guediawaye, all health care providers surveyed reported prescribing ACT DT and ORS/Zinc for uncomplicated malaria and diarrhea, respectively. In contrast, only $33.3 \%$ of respondents said they prescribe artesunate suppository as a pre-referral treatment of severe malaria (Table 5). 
Table 5. Use of the drug basket.

\begin{tabular}{ccccc}
\hline \multirow{2}{*}{ Drug names } & \multicolumn{2}{c}{ Guediawaye $(\mathrm{N}=12)$} & \multicolumn{2}{c}{ Pete $(\mathrm{N}=28)$} \\
\cline { 2 - 5 } & $\mathrm{n}$ & $\%$ & $\mathrm{n}$ & $\%$ \\
\hline ACT DT & 12 & 100 & 28 & 100 \\
Artésunate suppository & 4 & 33.3 & 15 & 53.6 \\
ORS/Zinc & 12 & 100 & 27 & 96.4 \\
Amoxicillin 250 mg DT & 10 & 83.3 & 28 & 100 \\
Total & - & 79 & - & 88 \\
\hline
\end{tabular}

In the Pete's HD, slightly lower proportions were found for the use of ACT DT (96.6\%), ORS/Zinc (93.1\%) and amoxicillin $250 \mathrm{mg}$ DT (96.6\%). About one in two providers (51.7\%) used artesunate suppository as a pre-referral treatment of severe malaria (Table 5).

\subsection{Training/Supervision}

\subsubsection{Stock Management}

No pharmaceutical depot manager of Guediawaye and Pete were trained in the management of priority life-saving medicines for children in the twelve months prior to the survey. Only $15.4 \%(2 / 13)$ and $7.7 \%(2 / 26)$ of the respondents were supervised, respectively.

\subsubsection{Utilization of the Priority Life-Saving Medicines for Children}

In Guediawaye, only one out twelve prescribers (8\%) were trained and supervised in the use of priority life-saving medicines for children. As for Pete, among the 28 respondents, only three (10.7\%) and four (14.28\%) were trained and supervised, respectively.

\section{Discussion}

The physical accessibility of essential drugs is an important component of an NDP [24]. The results for this indicator were not consistent across all drugs. On the one hand, the availability of ORS, zinc $20 \mathrm{mg}$ DT and RUTFs was satisfactory. On the other hand, that of amoxicillin $250 \mathrm{mg}$ DT, vitamin A 100,000 IU capsules, artesunate $50 \mathrm{mg}$ suppository and artesunate $200 \mathrm{mg}$ suppository was low. Similar results have been reported in Ethiopia [8] [22] and Guatemala [9]. The duration of stock-out of these products was long and could have implications for public health. Amoxicillin $250 \mathrm{mg}$ DT is the first-line treatment for pneumonia and can save more than 1.5 million children's lives if it were available in HFs [23]. Conversely, its absence could have an impact on child survival since pneumonia-related morbidity is an important part of outpatient visits and hospitalizations in low- and middle-income countries [27].

Vitamin A supplementation is a high-impact intervention, reducing all-cause mortality by $23 \%$ in children aged 6 to 59 months [28]. WHO recommends bi-annual supplementation for this age group [29]. MHSA integrated this inter- 
vention with other health services such as vaccination and weighing [30]. So, breaking up vitamin A could lead to missed opportunities for supplementation. Health professionals' difficulty in understanding the clinical efficacy of vitamin A and poor maternal demand may be the cause of its low availability [31].

In the HD of Pete, the low availability of antimalarial drugs may be linked to the pre-elimination context of malaria in the northern part of Senegal [32]. However, WHO recommends that the rectal artesunate be administered to children up to six years with severe malaria in areas where transfer delay should exceed six hours, as in remote rural areas [33]. In this regard, the low availability of rectal artesunate in this HD would be a concern since some HFs are hundreds of kilometers away from the reference HC. In Guediawaye, the main remark was that artesunate suppository had never been in stock in the HFs. This could be related to the fact that this HD is located in the capital where the transfer of severe malaria cases could be done quickly compared to rural areas.

Stock-outs in the public sector could contribute to the inaccessibility of medicines [8] and force people to visit community pharmacies that sell brand-name medicines [22] [34]. This results in high direct costs which represent a burden for patients and their families [35]. In Tanzania, ACT stock-outs increased household spending per episode of fever from US $\$ 0.14$ to US $\$ 1.76$ [36].

The absence of drugs in private HFs could be explained by the free health care policy for under-five children [23].

Stock-out can be linked to the multiplicity of international partners that intervene without coordination in the distribution channels, to the lack of local production of medicines and to insufficient funding [37].

It would be essential to manage these stock-outs by putting in place a comprehensive information system accessible to all stakeholders. Information on a risk of stock-out would offer prescribers the opportunity to find a solution to replace one drug with another and thus save time and reduce patient anxiety [38].

Similarly, quality information is important not only to estimate drug needs but also to know the state of stocks at all levels of the health system [39]. This information is provided in part by the stock card which is the basic element of drug management [40]. However, this study revealed that the stock cards were not established for certain drugs in the Pete's HD. This situation could lead to a poor estimate of needs and an accumulation of expired products [41]. The latter is indicative of poor management that may result from poor storage, poor recording of drug quantities, non-compliance with the "first-in, first-out" principle and irregular physical inventories [24]. Expired medicines are medical waste that is classified as pharmaceutical waste. Their presence in depots involves a major public health issue [41]. Indeed, the possible use of these products has clinical consequences such as therapeutic inefficiency and resistance which in turn entail additional costs for the patients [41]. According to a recent WHO report, substandard or falsified antimalarial drugs are responsible for 72,000 to 267,000 additional deaths per year in SSA [42]. These drugs may end up in the illicit market [41]. The inappropriate destruction of this waste can have an im- 
pact on the environment [43]. Faced with this situation, it would be essential to establish procedures for the management and destruction of expired medicines. One of the best ways to tackle this scourge is to minimize waste. Minimization requires the rational purchase and management of medicines [41]. At the same time, physical inventories should be regularly conducted, stock cards updated, and health professionals trained on the quantification of drug needs.

In addition, the data showed a poor availability of the pharmacovigilance form among prescribers. This could lead to the underreporting of adverse drug reactions (ADRs). Therefore, it would be essential to train health workers in good pharmacovigilance practices and inform them that ADRs and defect quality reporting forms are available on the website of the DPG [44] [45].

Rational use of drugs is a component of NDP [24]. In this study, most health professionals reported using ACT DT, ORS/Zinc and amoxicillin $250 \mathrm{mg}$ DT to treat uncomplicated malaria, diarrhea and pneumonia, respectively. This result is encouraging and could be linked to the existence of algorithms for the management of these diseases [46]. The regular holding of supervision of health workers will reinforce their adherence to these guidelines. On the other hand, the use of suppository artesunate as a pre-transfer treatment for severe malaria was low, thus promoting inappropriate prescribing. This situation could be explained by the low availability of rectal artesunate in the HFs as has been the case in Uganda [23]. Conversely, the presence of outdated artesunate stock may reflect its low utilization.

\section{Strengths and Limitation}

This study has two main strengths. The first is that it has explored the main components of a NDP namely access, quality and use of drugs. Second, it is one of the few studies to have evaluated the availability of inventory management and ARDs reporting tools.

The associated factors of drug use were not assessed, hence the need for further studies.

\section{Conclusion}

Access to priority life-saving medicines for children remains a challenge in Guediawaye and Pete. If the availability of zinc $20 \mathrm{mg}$ DT, ORS and RUTFs was satisfactory, that of antimalarial drugs, amoxicillin $250 \mathrm{mg}$ DT was, on the other hand, low. The reported use of these drugs was high except for the rectal form of artesunate. The study also revealed inadequate management practices with the presence of expired stocks in the depots. These results show that the distribution system should be improved and the private sector encouraged to source essential medicines for under-five children. Training and supervision of health professionals would also be needed in order to promote rational use and good stock control management practices of medicines. Additional studies should be conducted in other Senegalese HDs to better understand the barriers to accessing child health services. 


\section{Acknowledgements}

We thank the District Medical Officers for allowing us to do this study in the health facilities.

\section{Conflicts of Interest}

The authors declare no conflicts of interest regarding the publication of this paper.

\section{References}

[1] United Nations Inter-Agency Group for Child Mortality Estimation (2018) Levels \& Trend in Child Mortality [Internet]. The United Nations Children's Fund, New York.

https://childmortality.org/wp-content/uploads/2018/12/UN-IGME-Child-Mortality -Report-2018.pdf

[2] Agence Nationale de la Statistique et de la Démographie (2018) Enquête Démographique et de Santé Continue [Internet]. ANSD et ICF, Dakar. http://dhsprogram.com/pubs/pdf/FR345/FR345.pdf

[3] Fonds des Nations Unies pour l'Enfance (2016) La situation des enfants dans le monde: L'égalité des chances pour chaque enfant [Internet]. UNICEF, New York. https://www.unicef.org/french/publications/files/UNICEF SOWC 2016 French L AST.pdf

[4] Swain, T.R., Rath, B., Dehury, S., Tarai, A., Das, P., Samal, R., et al. (2015) Pricing and Availability of Some Essential Child Specific Medicines in Odisha. Indian Journal of Pharmacology, 47, 496-501. https://doi.org/10.4103/0253-7613.165197

[5] Liu, L., Oza, S., Hogan, D., Chu, Y., Perin, J., Zhu, J., et al. (2016) Global, Regional, and National Causes of Under-5 Mortality in 2000-15: An Updated Systematic Analysis with Implications for the Sustainable Development Goals. The Lancet, 388, 3027-3035. https://doi.org/10.1016/S0140-6736(16)31593-8

[6] Organisation Mondiale de la Santé (2015) La stratégie mondiale pour la santé de la femme, de l'enfant et de l'adolescent (2016-2030) [Internet]. OMS, Genéve. https://www.who.int/maternal child adolescent/documents/strategie-mondiale-fe mme-enfant-ado-2016-2030.pdf

[7] Organisation Mondiale de la Santé (2012) Médicaments vitaux prioritaires destinés aux mères et aux enfants [Internet]. OMS, Genéve. http://apps.who.int/medicinedocs/documents/s19895fr/s19895fr.pdf

[8] Sado, E. and Sufa, A. (2016) Availability and Affordability of Essential Medicines for Children in the Western Part of Ethiopia: Implication for Access. BMC Pediatrics, 16, Article No. 40. https://doi.org/10.1186/s12887-016-0572-3

[9] Anson, A., Ramay, B., de Esparza, A.R. and Bero, L. (2012) Availability, Prices and Affordability of the World Health Organization's Essential Medicines for Children in Guatemala. Global Health, 8, 22. https://doi.org/10.1186/1744-8603-8-22

[10] Organisation Mondiale de la Santé (2011) Médicaments prioritaires destinés aux mères et aux enfants [Internet]. OMS, Genéve. https://www.who.int/medicines/publications/frA4prioritymedicines.pdf

[11] Kade, K., Kingshott, E., Latimer, A., Nieuwenhuyus, B.J., Pacque, M., Fox, S., et al. (2013) Mise à l'échelle de l'usage des produits d'importance vitale pour les femmes, les enfants et les nouveaux-nés. Une boîte à outils pour le plaidoyer. PATH, Wash- 
ington DC.

[12] Hill, S., Yang, A. and Bero, L. (2012) Priority Medicines for Maternal and Child Health: A Global Survey of National Essential Medicines Lists. PLoS ONE, 7, e38055. https://doi.org/10.1371/journal.pone.0038055

[13] Ministère de la Santé et de la Prévention Médicale (2006) Politique Pharmaceutique Nationale [Internet]. MSPM, Dakar. http://apps.who.int/medicinedocs/documents/s18820fr/s18820fr.pdf

[14] Ministere de la Santé et de l'Action sociale (2018) Liste Nationale des Médicaments et Produits Essentiels du Sénégal [Internet]. MSAS, Dakar. https://www.dirpharm.net/images/sampledata/pdf/Liste nationale.pdf

[15] Ministere de la Santé et de l'Action Sociale (2014) Bulletin d'information pharmaceutique-Trimestriel numéro 3 [Internet]. MSAS, Dakar.

https://www.dirpharm.net/index.php/legislation/textes-legislatifs/category/2-bulleti n-d-information

[16] Organisation Mondiale de la santé, Health Action Internationale (2008) Mesurer les prix, l'accessibilité financière et les composantes des prix des médicaments [Internet]. OMS, Genève.

https://haiweb.org/wp-content/uploads/2015/07/Table-of-Contents-FR-MeasuringMedicine-Prices-Methodology.pdf

[17] Robertson, J., Forte, G., Trapsida, J.-M. and Hill, S. (2009) What Essential Medicines for Children Are on the Shelf? Bulletin of the World Health Organization, 87, 231-237. https://doi.org/10.2471/BLT.08.053645

[18] Alefan, Q., Amairi, R. and Tawalbeh, S. (2018) Availability, Prices and Affordability of Selected Essential Medicines in Jordan: A National Survey. BMC Health Services Research, 18, Article No. 787. https://doi.org/10.1186/s12913-018-3593-9

[19] Agence Nationale de Statistique et de la Démographie (2018) Enquête Continue sur la Prestation des Services de Soins de Santé (ECPSS) 2017 [Internet]. ANSD et ICF, Dakar. http://dhsprogram.com/pubs/pdf/SPA27/SPA27.pdf

[20] Ministère de la Santé et de l'Action Sociale. Système d'information sanitaire/MSAS [Internet]. https://senegal.dhis2.org/dhis/dhis-web-commons/security/login.action

[21] Ministère de la Santé et de l'Action Sociale (2018) Cartographie du district sanitaire de Pété. MSAS-RM-DS Pété, Pété.

[22] Abrha, S., Tadesse, E., Atey, T.M., Molla, F., Melkam, W., Masresha, B., et al. (2018) Availability and Affordability of Priority Life-Saving Medicines for Under-Five Children in Health Facilities of Tigray Region, Northern Ethiopia. BMC Pregnancy Childbirth, 18, 1-9. https://doi.org/10.1186/s12884-018-2109-2

[23] Nsabagasani, X., Ogwal-Okeng, J., Mbonye, A., Ssengooba, F., Muhumuza, S. and Hansen, E.H. (2015) Availability and Utilization of the WHO Recommended Priority Lifesaving Medicines for under Five-Year Old Children in Public Health Facilities in Uganda: A Cross-Sectional Survey. Journal of Pharmaceutical Policy and Practice, 8, 1-7. https://doi.org/10.1186/s40545-015-0038-2

[24] Organisation Mondiale de la Santé (1996) Indicateurs de suivi de la mise en œuvre des politiques pharmaceutiques nationales [Internet]. OMS, Généve. https://apps.who.int/medicinedocs/pdf/whozip15f/whozip15f.pdf

[25] Ministère de la Santé (2013) Rapport d'enquête sur les services de sante Disponibilité et capacité opérationnelle des services de santé au Bénin [Internet]. MS, Cotonou.

https://www.who.int/healthinfo/systems/SARA Benin 2013 fullreport.pdf 
[26] Organisation mondiale de la Santé (2015) Mesurer la disponibilité et la capacité opérationnelle des services (SARA): Un outil d'évaluation des établissements de santé: Manuel de référence, version 2.2, Révision Juillet 2015 [Internet]. OMS, Généve.

https://apps.who.int/iris/bitstream/handle/10665/149026/WHO HIS HSI $2014.5 \mathrm{f}$ re.pdf? sequence $=1$ \&isAllowed $=y$

[27] Campbell, H., el Arifeen, S., Hazir, T., O’Kelly, J., Bryce, J., Rudan, I., et al. (2013) Measuring Coverage in $\mathrm{MNCH}$ : Challenges in Monitoring the Proportion of Young Children with Pneumonia Who Receive Antibiotic Treatment. PLOS Medicine, 10, e1001421. https://doi.org/10.1371/journal.pmed.1001421

[28] Hendricks, M., Beardsley, J., Bourne, L., Mzamo, B. and Golden, B. (2007) Are Opportunities for Vitamin A Supplementation Being Utilised at Primary Health-Care Clinics in the Western Cape Province of South Africa? Public Health Nutrition, 10, 1082-1088. https://doi.org/10.1017/S1368980007699522

[29] Berde, A.S., Bester, P. and Kruger, I.M. (2019) Coverage and Factors Associated with Vitamin A Supplementation among Children Aged 6-59 Months in Twenty-Three Sub-Saharan African Countries. Public Health Nutrition, 22, 1770-1776. https://doi.org/10.1017/S1368980018004056

[30] Horton, S., Blum, L.S., Diouf, M., Ndiaye, B., Ndoye, F., Niang, K., et al. (2018) Delivering Vitamin A Supplements to Children Aged 6-59 Months: Comparing Delivery through Campaigns and through Routine Health Services in Senegal. Current Developments in Nutrition, 2, nzy006. https://doi.org/10.1093/cdn/nzy006

[31] Berger, R., Courtright, P. and Barrows, J. (1995) Vitamin A Capsule Supplementation in Malawi Villages: Missed Opportunities and Possible Interventions. American Journal of Public Health, 85, 718-719. https://doi.org/10.2105/AJPH.85.5.718

[32] Ministère de la Santé et de l'Action Sociale (2017) Bulletin épidémiologique du paludisme au Sénégal [Internet]. MSAS, Dakar. http://www.pnlp.sn/wp-content/uploads/2017/12/Bulletin-Epidemiologique-du-Pal udisme-au-SENEGAL-Trimestriel-N\%C2\%B003 2017-vf.pdf

[33] Organisation Mondiale de la Santé (2017) Traitement de pré transfert du paludisme grave avec de l'artésunate par voie rectale [Internet]. Genève.

https://apps.who.int/iris/bitstream/handle/10665/259484/WHO-HTM-GMP-2017.1 9-fre.pdf;jsessionid=6EE46B073BB440FF30F43B5F5434B510? sequence $=1$

[34] Frost, A., Wilkinson, M., Boyle, P., Patel, P. and Sullivan, R. (2016) An Assessment of the Barriers to Accessing the Basic Package of Health Services (BPHS) in Afghanistan: Was the BPHS a Success? Global Health, 12, 71.

https://doi.org/10.1186/s12992-016-0212-6

[35] Organisation Mondiale de la Santé (2014) Accès aux médicaments essentiels-Rapport du Secrétariat [Internet]. Genève.

https://apps.who.int/iris/bitstream/handle/10665/170818/A67 30-fr.pdf?sequence= $\underline{1 \text { \&isAllowed }=\mathrm{y}}$

[36] Mikkelsen-Lopez, I., Tediosi, F., Abdallah, G., Njozi, M., Amuri, B., Khatib, R., et al. (2013) Beyond Antimalarial Stock-Outs: Implications of Health Provider Compliance on Out-of-Pocket Expenditure during Care-Seeking for Fever in South East Tanzania. BMC Health Services Research, 13, Article No. 444. https://doi.org/10.1186/1472-6963-13-444

[37] Barbereau, S. (2013) L'approvisionnement en médicaments dans les pays en voie de développement-Il faut sauver les centrales d'achats publiques de médicaments en 
Afrique. Médecine et Santé Tropicales, 23, 251-255.

[38] Ottino, G., Lebel, D., Bussières, J.F. and Bourdon, O. (2012) Gestion des ruptures d'approvisionnement de médicaments: Perspectives en France, aux Etats-Unis et au Canada. The Canadian Journal of Hospital Pharmacy, 65, 37-42. https://doi.org/10.4212/cjhp.v65i1.1102

[39] Briggs, J., Embrey, M., Maliqi, B., Hedman, L. and Requejo, J. (2018) How to Assure Access of Essential RMNCH Medicines by Looking at Policy and Systems Factors: An Analysis of Countdown to 2015 Countries. BMC Health Services Research, 18, Article No. 952. https://doi.org/10.1186/s12913-018-3766-6

[40] Ministère de la Sante, des Affaires Sociales et de la Famille. Manuel de gestion des médicaments dans les centres de sante intégrés et hopitaux de référence [Internet]. MSASF, Brazaville.

http://afrolib.afro.who.int/documents/2009/fr/Cg-GestionMedicaments.pdf

[41] De Solère, M. (2012) Accessibilité aux médicaments en Afrique de l'ouest: Problématique de la prise en charge des médicaments périmés dans le secteur pharmaceutique public. Étude de cas par PSF37 au Bénin [Thesis]. [Rouen]: U.F.R de Médecine et de Pharmacie de Rouen, 185 p.

[42] Organisation Mondiale de la Santé (2018) Étude de l'impact socioéconomique et sur la santé publique des produits médicaux de qualité inférieure et falsifiés [Internet]. OMS, Genève. http://dirpharm.sn/pdf/ProduitsMedicauxFalsifieesOMS.pdf

[43] Paut Kusturica, M., Tomas, A. and Sabo, A. (2017) Disposal of Unused Drugs: Knowledge and Behavior among People around the World. Reviews of Environmental Contamination and Toxicology, 240, 71-104.

https://doi.org/10.1007/398 2016_3

[44] Ministère de la Santé et de l'Action Sociale (2014) Fiche de notification d'effet indesirable susceptible d'etre dû a un medicament ou a un autre produit de sante [Internet]. Dakar.

http://www.dirpharm.net/images/sampledata/pdf/FicheNotificationSystemeNationa 1PV2014.pdf

[45] Ministère de la Santé et de l'Action Sociale. Fiche de signalement d'un médicament suspecté d'un défaut de qualité pouvant entrainer un risque pour la santé/sécurité du patient [Internet]. MSAS, Dakar.

http://www.dirpharm.net/images/sampledata/pdf/fiche signalement.pdf

[46] Ministère de la Santé et de l'Action Sociale (2014) Guide du formateur de l'acteur communautaire de soins sur les maladies prioritaires de l'enfant [Internet]. MSAS, Dakar.

http://www.pnlp.sn/wp-content/uploads/2018/02/AIDE-MEMOIRE-DSDOM.pdf 